\title{
Articular cartilage repair and the evolving role of regenerative medicine
}

This article was published in the following Dove Press journal:

Open Access Surgery

12 October 2010

Number of times this article has been viewed

\author{
Pieter K Bos' \\ Marloes L van Melle' \\ Gerjo JVM van Osch ${ }^{1,2}$ \\ 'Department of Orthopaedic \\ Surgery, Erasmus MC, Rotterdam, \\ the Netherlands; ${ }^{2}$ Department of \\ Otorhinolaryngology, Erasmus MC, \\ Rotterdam, the Netherlands
}

Correspondence: PK Bos Department of Orthopaedic Surgery, Room HS 105, Erasmus University Medical Center, PO Box 2040, 3000 CA

Rotterdam, the Netherlands

Tel +3I I0 7034686

Fax +31107031002

Email p.k.bos@erasmusmc.nl
Abstract: Among the growing applications of regenerative medicine, clinical articular cartilage repair has now been used for 2 decades and forms a successful example of translational medicine. Cartilage is characterized by a limited intrinsic repair capacity following injury. Articular cartilage defects cause symptoms, are not spontaneously repaired, and are generally believed to result in early osteoarthritis. Marrow stimulation techniques, osteochondral transplantation, and cell-based therapies, such as autologous chondrocyte implantation (ACI) and use of mesenchymal stem cells (MSCs), are used for tissue regeneration, symptom relief, and prevention of further joint degeneration. The exact incidence of cartilage defects and the natural outcome of joints with these lesions are unclear. Currently available cartilage repair techniques are designed for defect treatment in otherwise healthy joints and limbs, mostly in young adults. The natural history studies presented in this review estimated that the prevalence of cartilage lesions in this patient group ranges from 5\% to $11 \%$. The background and results from currently available randomized clinical trials of the three mostly used cartilage repair techniques are outlined in this review. Osteochondral transplantation, marrow stimulation, and ACI show improvement of symptoms with an advantage for cell-based techniques, but only a suggestion that risk for joint degeneration can be reduced. MSCs, characterized by their good proliferative capacity and the potential to differentiate into different mesenchymal lineages, form an attractive alternative cell source for cartilage regeneration. Moreover, MSCs provide a regenerative microenvironment by the secretion of bioactive factors. This trophic activity is believed to limit damage and stimulate intrinsic regenerative responses. Finally, important clinical issues are discussed, including techniques to study the role of implanted cells in tissue regeneration using cell labeling and cell tracking, the improvement of cartilage integration, the use of delayed gadolinium-enhanced magnetic resonance imaging of cartilage for early judgment of joint degeneration/regeneration, and the influence of regulatory rules for therapeutic application development.

Keywords: articular cartilage, repair, imaging, techniques

\section{Introduction}

Cartilage is characterized by a limited intrinsic repair capacity following injury. Articular cartilage lesions are frequently associated with symptoms such as pain, effusion, locking phenomena, and disturbed function. Moreover, these lesions are generally believed to progress to early osteoarthritis (OA).${ }^{1-3}$ Regenerative medicine, including in situ induction of cartilage tissue, use of tissue-engineered cartilage constructs, or cell-based therapies (autologous chondrocytes or mesenchymal stem cells [MSCs]) is used for tissue regeneration, symptom relief, and prevention of further degeneration. 
Mankin, in his editorial accompanying Brittberg's pioneering paper in the New England Journal of Medicine on autologous chondrocyte implantation (ACI) in 1994, ${ }^{4}$ discussed the difficulties of treating cartilage injuries and stated: the tissue is difficult to work with, injuries to joint surface - whether traumatic or degenerative - are unforgiving, and the progression to $\mathrm{OA}$ is sometimes so slow that we delude ourselves into thinking we are doing better than we are ${ }^{5}$ clinical and basic scientists have made much progress since 1994 in understanding cartilage disease and degeneration and also have made progress in biological repair of it. However, Mankin's remarks illustrate that the translation from basic knowledge and experimental treatments toward successful and durable repair of cartilage defects and osteoarthritic joints is difficult. The treatment goals of cartilage pathology are symptom relief, improvement of joint congruence by restoring the joint surface with the best possible tissue, and prevention of further joint degeneration.

Articular cartilage is a highly organized avascular tissue composed of chondrocytes embedded within an extracellular matrix of collagens, proteoglycans, and noncollagenous proteins. It makes painless, low friction movement of synovial joints possible. Hyaline cartilage covers the subchondral bone and forms the articulating surface of synovial joints. It functions as a mechanical shock absorber and distributes the applied load over the subchondral bone. The regeneration capacity of articular cartilage following injury is considered to be limited. Partial-thickness articular cartilage defects, limited to the cartilage itself, are not repaired, and fullthickness defects are repaired with fibrocartilage, ${ }^{6}$ which has inferior biological and biomechanical properties compared with hyaline cartilage. ${ }^{?}$

In this review, we will give a description of the epidemiology and natural history of cartilage lesions and provide an overview of current regenerative cartilage repair techniques, review outcomes from randomized clinical trials (RCTs), and give insight on new developments with use of MSCs and tissue-derived progenitor cells.

\section{Epidemiology and natural history of cartilage injury}

The exact incidence of symptomatic chondral lesions and the natural outcome of joints with osteochondral lesions are not well defined. A prospective study of 1,000 consecutive knee arthroscopies revealed International Cartilage Repair Society (ICRS) grades III and IV chondral lesions, ${ }^{8}$ with an area of at least $1 \mathrm{~cm}^{2}$, in patients younger than 40,45 , and 50 years of age $\left(5.3 \%, 6.1 \%\right.$, and $7.1 \%$, respectively). ${ }^{9}$
The mean osteochondral defect area was $2.1 \mathrm{~cm}^{2}$. Another prospective study of 993 knee arthroscopies ${ }^{10}$ in patients with a median age of 35 years shows that $11 \%$ had full-thickness articular cartilage defect (ICRS grades III and IV), and 6\% had a lesion size of more than $2 \mathrm{~cm}^{2}$. Prospective arthroscopic evaluation of traumatic knee hemarthrosis patients showed $8 \%-20 \%$ osteochondral lesions, frequently associated with injury to the anterior cruciate ligament (ACL). ${ }^{11-13} \mathrm{Curl}$ et a ${ }^{14}$ retrospectively reviewed 31,516 knee arthroscopies of patients in all age groups and reported chondral lesions in 19,827 (63\%) patients, with a mean of 2.7 lesions per knee. The incidence of grade III lesions was $41 \%$ and grade IV lesions $19 \%$. In the younger population (age $<40$ years), however, the incidence of unipolar grade IV lesions of the femoral condyle was only $5 \%$. Thus, the prevalence of isolated osteochondral defects ranges from $5 \%$ to $11 \%$ in the young patients and up to $63 \%$ in the patients overall.

It is unclear which chondral lesions give symptoms. Many of the detected lesions are asymptomatic and, therefore, the exact incidence in the general population is unknown. It is likely that symptoms and joint degeneration are dependent on lesion size, location, and patient characteristics.

Shelbourne et $\mathrm{al}^{15}$ reported a series of 125 Outerbridge grades III and IV ${ }^{16}$ cartilage defects (mean size $1.7 \mathrm{~cm}^{2}$, 60 medial, 65 lateral compartment, and intact menisci) discovered during 2,770 ACL reconstructive procedures. These authors showed, at a mean follow-up of 8.7 years, very little difference in clinical outcome following ACL repair between patients with a chondral defect and those without a defect. There was no difference between groups with regard to radiological degenerative changes.

However, it may take up to more than 20 years before clinical and radiological degenerative changes come forward. Linden $^{17}$ showed in a retrospective radiological study on osteochondritis dissecans (OCD) of the knee in adult patients, with a $32.5 \pm 7.5$ year follow-up, mild radiological deterioration in 14/44 joints and severe changes in 29/44 joints.

In a recent natural history study in 2010, Widuchowski et al ${ }^{18}$ retrospectively analyzed 4,121 consecutive knee arthroscopies. In the patient group younger than 35 years, there were 37 single-isolated Outerbridge grades III and IV lesions within the weight-bearing areas of the femorotibial compartments and the patella. At a mean follow-up of 15.3 years, the authors found no difference in OA severity between the injured and the uninjured knees, indicating that severe isolated chondral defects may have limited influence on the development of knee OA. 
Gelber et $\mathrm{al}^{19}$ followed 1,321 former medical students with joint injuries, with median follow-up of 36 years, and found that $13.9 \%$ of students with knee injuries progressed to fully developed knee OA by the age of 65 years compared with $6 \%$ in controls without joint injury. In this frequently cited article, however, from the 111 isolated knee injuries, just 8 sustained an isolated cartilage injury. More severe injuries including tibial plateau fractures, knee dislocation, and open fractures are considered to have a higher risk for OA development.

In conclusion, most authors assume that cartilage lesions, frequently associated with other articular injuries, progress to joint degeneration. However, it is difficult to exactly predict which lesions will benefit from cartilage repair. Whether a cartilage lesion causes progression toward OA may depend on lesion size, location, preinjury joint degeneration, limb alignment, and other patient characteristics.

The available articular cartilage repair techniques are not designed to treat degenerative joint disease, eg, OA. However, several authors have used the described techniques or combinations of it to treat degenerative joint disease. ${ }^{20,21}$ For example, they used microfracturing ${ }^{20}$ and/or meniscus transplantation or joint realignment procedures for knee OA cases. ${ }^{21}$ To date, there are no randomized clinical studies reporting the outcome of treatment of these patient groups.

OA affected nearly 27 million or $12.1 \%$ of the adult population in the United States in $2008 .^{22} \mathrm{OA}$ is the fifth leading cause of disability in older Americans after cardiovascular, cerebrovascular, and pulmonary diseases. ${ }^{23}$ It is estimated that the number of adults in the United States with arthritis disease will reach up to 67 million, or $25 \%$ of the population, by $2030 .{ }^{24}$ Successful repair techniques for isolated cartilage defects in otherwise healthy joints may, in the future, be translated to treatment of more extensive joint degeneration such as OA. Biological repair and possible disease modification, with the use of regenerative medicine techniques, may thereby decrease the expected medical and economic burdens.

\section{Current clinical methods of repair}

The primary goal in articular cartilage repair procedures should be defect filling and restoration of the articular surface with the best possible repair tissue. Long-lasting biomechanical properties resembling that of hyaline cartilage and a full integration with the surrounding articular cartilage should result in pain-free movement and prevent early joint degeneration. Surgical treatment options for cartilage repair include symptomatic treatments like debridement and lavage, osteochondral autograft transplantation (OAT), marrow stimulation techniques (Pridie drilling or microfracture), ACI, and tissue engineering techniques using cells and biomaterials to replace damaged or lost cartilage and bone.

Focusing on articular cartilage repair, we can distinguish three main techniques for biological repair of cartilage defects: osteochondral transplantation (OAT or mosaicplasty), subchondral marrow stimulation (Pridie drilling or microfracture), and ACI.

In OAT or mosaicplasty, introduced in the $1990 \mathrm{~s}$, autologous osteochondral biopsy plugs are harvested from relatively nonweight-bearing areas of the joint and subsequently implanted in a mosaic-like pattern in debrided cartilage defects. ${ }^{25,26}$ OAT or mosaicplasty, popularized by Hangody et $\mathrm{al}^{25}$ and Bobic, ${ }^{26}$ is recommended for defects limited to between 1 and $4 \mathrm{~cm}^{2} .{ }^{27}$ For these small- to medium-sized defects, good results have been reported in terms of function scores and histology for follow-up up to 7 years after treatment. ${ }^{25,27}$ Drawbacks of this technique are limited availability of donor tissue and donor site morbidity. ${ }^{25,27,28}$ In this review, we will focus on the two techniques that can be characterized as regenerative medicine: the microfracture technique and ACI with or without matrix augmentation.

\section{Microfracture}

Already in the 1950s, it was hypothesized that accessing the bone marrow could be helpful in the repair of cartilage defects. The general hypothesis behind all marrow stimulation techniques is that MSCs present in the bone marrow are responsible for the formation of fibrocartilaginous tissue that fills the initial defect. ${ }^{6,29}$ Marrow stimulation in the microfracture technique is achieved by cortical penetration with an awl; in Pridie drilling, a drill or Kirchner-wire is used. The microfracture technique was introduced in the 1980s and is considered as an evolved form of Pridie drilling, and generally accepted to result in clinically more favorable outcomes, which is attributed to the absence of thermal damage in the microfracture technique, although the two techniques have never been compared directly. After debridement of the defect, conical holes of $0.5-1 \mathrm{~mm}$ in diameter and $4 \mathrm{~mm}$ deep are punched all over the defect at a distance of 3-4 mm apart with specialized tapered awls. Consequently, a blood clot fills the defect followed by ingrowth of bone marrow cells. ${ }^{30-34}$

Using the equine medial femorotibial joint as a model for the medial femoral condyle of the human knee, many aspects of the microfracture technique have been studied. ${ }^{35-40}$ A finding that was subsequently translated into clinical 
practice was the importance of the removal of the calcified cartilage layer prior to creation of the holes. ${ }^{36,39}$ Insufficient removal can lead to dislocation of the clot, where damaging the subchondral plate can result in overgrowth of subchondral bone, causing decrease of repair tissue volume and compromised mechanical properties. ${ }^{36,39,41,42}$

For optimal results, patients should preferably be younger than 45 years of age, have a body mass index less than 30 and experience symptoms (activity related pain, swelling, locking, and catching) for less than 1 year. The defect should be isolated from other lesions and should be smaller than $4 \mathrm{~cm}^{2}$. An intact rim of cartilage should surround the defect to ensure that the bone marrow clot stays in place. ${ }^{33}$ Contraindications are degenerative joint changes, axial malalignment $>5^{\circ}$ for femoral condyle defects, tumors, infections, meniscus pathology that requires treatment, and high-grade ligament instabilities. ${ }^{33,36}$ Microfracture is often coupled to a specific rehabilitation program. ${ }^{43}$ Initially, weight-bearing is avoided, followed by controlled partial weight-bearing, to provide nutrients and to provide mechanical stimuli. ${ }^{33,34,43-46}$ Return to full premorbid activities is generally achieved at 15-18 months after surgery. ${ }^{43}$ Improvement in terms of pain and function is widely reported up to 24 months after surgery; however, the long-term durability is debated; return of complaints is generally expected. Upon histological analysis of biopsies taken at 2 years after treatment, $69 \%$ of treated lesions were found to consist of mainly fibrocartilaginous tissue, whereas $11 \%$ predominantly contained hyaline cartilage. ${ }^{47}$ The fibrocartilaginous repair tissue contains more type I collagen and less proteoglycan compared with native articular cartilage, indicating that the biochemical and biomechanical properties are not equal to those of the native articular cartilage. ${ }^{35,37-39,48}$

Many augmentation strategies are currently being investigated in order to improve the long-term outcome of the microfracture technique, eg, autologous matrix-induced chondrogenesis (AMIC) involving type I/III collagen scaffolds (Geistlich Pharma AG, Wolhusen, Switzerland) or chitosan-glycerol phosphate-based BST-CarGel ${ }^{\circledR}$ scaffold (Biosyntech Inc, Laval, Canada). Good results were reported for the AMIC type I/III collagen scaffold technique. ${ }^{49}$ Improvement of repair tissue quality and ICRS II scores compared with conventional microfracture has been found for chitosan-glycerol phosphate-based BST-CarGel, which is currently being evaluated in a multicenter clinical trial. ${ }^{50-53}$ Other augmentation strategies consist of hyaluronic acid injections or biomaterials with incorporated growth factors. ${ }^{32,54-57}$ Most of these strategies are currently in preclinical stages. ${ }^{56}$

\section{Autologous chondrocyte implantation}

The ACI technique for clinical treatment of human cartilage defects was first reported in $1994 .{ }^{4}$ In summary, a cartilage biopsy is taken arthroscopically from a nonweight-bearing area of the joint. Cartilage biopsies are enzymatically digested to isolate chondrocytes. The chondrocytes are expanded in monolayer culture. In a second open procedure that can take place 6 weeks up to 18 months after the biopsy, a periosteal flap, harvested from the tibia, is placed over the cartilage defect, fixed with sutures, and sealed with fibrin glue after which a solution of expanded chondrocytes is injected underneath the flap., ${ }^{4,58}$ This first-generation ACI procedure is also known as ACI-P, based on the use of the periosteal flap. Leakage of cells, uneven distribution of chondrocytes, and hypertrophy of the periosteal flap were reported. ${ }^{58,59} \mathrm{In}$ the second-generation ACI procedure, a collagen membrane is used to replace the periosteal flap, which is also known as ACI-C. ${ }^{58}$ Several tissue engineering-based approaches are classified as the third generation of ACI, which means that cells are cultured on a biodegradable membrane or scaffold prior to placement into the defect, eg, matrix-induced ACI (MACI). In this MACI technique, chondrocytes are precultured on a porcine type I/III collagen membrane. Another approach is the use of characterized chondrocyte implantation (CCI) marketed as ChondroCelect ${ }^{\circledR}$ (TiGenix NV, Leuven, Belgium), in which autologous chondrocytes are characterized based on specific marker proteins, and expansion is standardized. ${ }^{60,61}$ With these emerging tissue engineering strategies, the possibility to perform ACI procedures arthroscopically gains more interest. ${ }^{60,62,63}$ The presence of cartilage damage at the opposing surface of the joint is a contraindication for ACI. ${ }^{58}$ Malalignment and ligamentous instability should be corrected prior to treatment. ${ }^{58,64}$ For optimal results, prevalence of symptoms should be less than 2 years, and the cartilage defect should be an isolated focal lesion. ${ }^{58}$ As for microfracture, an intact rim of cartilage should surround the defect to allow suturing of the periosteal flap, membrane, or scaffold. Damaging the subchondral bone is to be avoided to prevent the formation of fibrocartilaginous tissue due to bone marrow invasion. ${ }^{58}$ In contrast to the microfracture technique, for ACI no relationship between defect size and clinical outcome was found, which implies that ACI can be applied for cartilage defects of all sizes ${ }^{65}$ ACI treatment of cartilage defects is, as for microfracture, followed by a rehabilitation program involving restricted weight-bearing and use of continuous passive motion. Return to daily activities and light sports is generally achieved at $4-6$ months after treatment. ${ }^{58,66}$ Good to excellent outcomes have been reported 
for long-term (up to 7 years) follow-up of femoral condyle lesions treated with ACI, with indications of clinical outcome improvement over the years. ${ }^{66}$ Histological biopsy studies ${ }^{67}$ have shown that ACI repair can result in repair tissue of varying morphology, ranging from predominantly hyaline $(22 \%)$ through mixed (48\%) to predominantly fibrocartilage. The success rate of ACI reported in long-term durability studies varies from $69 \%$ at 10 -year follow-up ${ }^{68}$ to $84 \%$ at 7.4 -year follow-up. ${ }^{66}$ Failures are reported within the first years following treatment; good results at short-term follow-up are generally sustained at long-term follow-up. ${ }^{66,68}$

ACI was also found to result in improved clinical outcome when applied in patients with large cartilage defects that failed to repair in a previous treatment. ${ }^{69}$ However, this finding is debated; poor clinical outcome has been reported for patients undergoing ACI or MACI after failing mosaicplasty or ACI ${ }^{70} \mathrm{~A}$ limitation in ACI and its derivatives is the fact that chondrocytes tend to dedifferentiate during monolayer expansion, which decreases their extracellular cartilage matrix formation potential. ${ }^{71}$ For ACI, a widely used animal model is lacking due to reported variations in expansion and other characteristics of autologous chondrocytes over different species. ${ }^{72}$

Among the various types of cartilage, of interest are two distinct different cartilage types in the growing skeleton: (1) growth plate cartilage and (2) hyaline or articular cartilage. In growth plate cartilage, chondrocytes proliferate, become hypertrophic, and terminally differentiate. This process of maturation leads to cell death, followed by calcification of the tissue, and chondrocytes are replaced by osteoblasts. In the growing joint hyaline cartilage, chondrocytes proliferate and form the extracellular matrix, resulting in adult hyaline cartilage, with chondrocytes lying in low densities in a tight extracellular matrix. For ACI regenerative cartilage medicine, one of the challenges is to culture-expand cells to sufficient numbers for tissue regeneration while preventing hypertrophy, terminal differentiation, and calcification of the repair tissue. ${ }^{73}$

\section{Randomized clinical trials}

Many case studies and clinical trials on the above-described techniques have been published during the last 2 decades. In addition, several (systematic) reviews on ACI or cartilage repair techniques in general have been published during recent years ${ }^{2,32,36,48,64,74-81}$ expressing the growing interest of the community in the possibilities of these techniques. For this review, we decided to highlight the RCTs. The microfracture technique, popularized by Steadman, ${ }^{36}$ is often used as a first treatment for cartilage defects and has become the control treatment in several prospective studies evaluating other more extensive surgical interventions such as ACI. We aim to provide an overview of RCTs involving ACI or its derivatives, microfracture, or both. The study and patient characteristics of all available RCTs are shown in Table 1. The outcome parameters and RCT quality scores are summarized in Table 2. The quality of presented RCTs comparing the different cartilage repair techniques was assessed according to Jadad et al. ${ }^{82}$

In 2003 Horas et al ${ }^{83}$ conducted a prospective RCT in which femoral condyle lesions of 40 patients were treated either with ACI-P or OAT. For both treatments, improvement of Lysholm Knee Scoring Scale (LKSS) scores compared with preoperative levels was reported; however, the increase was significantly slower for ACI-P-treated patients compared with OAT-treated patients at follow-up after 6, 12, and 24 months. ${ }^{83}$

In 2003 Bentley et $\mathrm{al}^{84}$ reported their findings of a prospective RCT in which 100 patients with symptomatic lesions of the articular cartilage of the knee were treated either with ACI-P/C or mosaicplasty. At 1 year after treatment, $82 \%$ of the ACI-P/C-treated group showed good or excellent results in ICRS grade arthroscopic results against 34\% of the mosaicplasty-treated group. Upon functional assessment (Cincinnati and Stanmore scores), 88\% of the ACI-P/C-treated group had good or excellent results, whereas in the mosaicplasty, 69\% was reported. It has to be noted that in this study patients with cartilage lesions over $4 \mathrm{~cm}^{2}$ in size were treated with mosaicplasty. Also, the rehabilitation program was similar for both treatment groups, whereas different programs are recommended for ACI and mosaicplasty. ${ }^{27,84}$

Bartlett et $\mathrm{al}^{70}$ reported their results of a prospective RCT study of ACI-C vs MACI in 2005. Ninety-one patients were randomized to one of the treatments. No significant differences were observed at 1 year after treatment in terms of ICRS scores, histological examination, and functional Cincinnati knee scores. Bartlett et $\mathrm{al}^{70}$ concluded that although no significant differences were found between the two treatments, MACI is technically more attractive due to factors like quicker surgery and the possibility not to use sutures; however, more long-term studies are required.

ACI-P and mosaicplasty were compared in a multicenter RCT by Dozin et al in $2005 .{ }^{85}$ Forty-seven patients were treated with arthroscopic debridement and subsequently randomized to one of the treatments. Debridement alone resulted in improvement to such an extent that 14 patients (31.8\%) were clinically asymptomatic and were not subjected 
Table I Overview of RCTs on cartilage defect repair techniques

\begin{tabular}{|c|c|c|c|c|c|}
\hline Author & Treatments (n) & Patient age (y) & Defect size $\left(\mathrm{cm}^{2}\right)$ & $\begin{array}{l}\text { Longest } \\
\text { follow-up, mo }\end{array}$ & $\begin{array}{l}\text { Outcome } \\
\text { measures }\end{array}$ \\
\hline \multirow[t]{4}{*}{ Horas et $\mathrm{a}^{83}$} & $\mathrm{ACl}-\mathrm{P}(20)$ & $31.4(18-42)$ & $3.9(3.2-5.6)$ & 24 & LKSS \\
\hline & OAT $(20)$ & $35.4(21-44)$ & & & Tegner \\
\hline & & & & & SEM \\
\hline & & & & & Histology \\
\hline \multirow[t]{4}{*}{ Bentley et $\mathrm{a}^{84}$} & $\mathrm{ACl}-\mathrm{P}$ and & $30.9(16-49)$ & $4.66(I-12)$ & 12 & Cincinnati \\
\hline & $\mathrm{ACl}-\mathrm{C}(58)$ & $31.6(20-48)$ & $4.66(I-12)$ & & Stanmore \\
\hline & $\mathrm{MP}(42)$ & & & & ICRS \\
\hline & & & & & Histology \\
\hline \multirow[t]{4}{*}{ Bartlett et al ${ }^{70}$} & $\mathrm{ACl}-\mathrm{C}(44)$ & 33.7 (I5-49) & $6(1.5-16)$ & 12 & Cincinnati \\
\hline & $\mathrm{MACl}(47)$ & $33.4(17-47)$ & $6.1(I-22)$ & & Stanmore \\
\hline & & & & & VAS \\
\hline & & & & & Histology \\
\hline \multirow[t]{2}{*}{ Dozin et $\mathrm{a}^{85}$} & $\mathrm{ACl}-\mathrm{P}(22)$ & $29.6( \pm 7.3)$ & $1.97( \pm 0.43)$ & 36 & LKSS \\
\hline & OAT (22) & $27.9( \pm 8.1)$ & $1.9( \pm 0.45)$ & & IKDC \\
\hline \multirow[t]{4}{*}{ Gudas et $\mathrm{a}^{86}$} & OAT (28) & $24.6( \pm 6.54)$ & $2.8( \pm 0.65)$ & 36 & ICRS \\
\hline & MF (29) & $24.3( \pm 6.8)$ & $2.77( \pm 0.68)$ & & HSS \\
\hline & & & & & MRI \\
\hline & & & & & Histology \\
\hline \multirow[t]{3}{*}{ Gooding et $\mathrm{al}^{87}$} & ACl-P (33) & $30.5(15-52)$ & $4.54(I-12)$ & 24 & Cincinnati \\
\hline & $\mathrm{ACl}-\mathrm{C}(35)$ & $30.5(16-49)$ & & & ICRS \\
\hline & & & & & Histology \\
\hline \multirow[t]{8}{*}{ Knutsen et $\mathrm{al}^{47,88}$} & $\mathrm{ACl}-\mathrm{P}(40)$ & 33.3 & 5.1 & 60 & LKSS \\
\hline & MF $(40)$ & 31.1 & 4.5 & & Kellgren \\
\hline & & & & & and \\
\hline & & & & & Lawrence \\
\hline & & & & & ICRS \\
\hline & & & & & Tegner \\
\hline & & & & & SF-36 \\
\hline & & & & & Histology \\
\hline \multirow[t]{2}{*}{ Saris et al $\mathrm{a}^{61,89}$} & $\mathrm{CCl}(57)$ & $33.9( \pm 8.5)$ & $2.5(I-5)$ & 36 & KOOS \\
\hline & $M F(6 I)$ & $33.9( \pm 8.6)$ & & & MRI \\
\hline
\end{tabular}

Notes: Characteristics on treatment groups, number of patients per treatment, defect sizes, duration of after treatment follow-up, and the applied outcome measures are presented.

Abbreviations: RCTs, randomized clinical trials; ACI-P, first generation autologous chondrocyte implantation (with periosteal coverage); OAT, osteochondral autograft transplantation; LKSS, Lysholm Knee Scoring Scale; SEM, scanning electron microscopy; ACI-C, second generation autologous chondrocyte implantation (with collagen coverage); MP, mosaicplasty; ICRS, International Cartilage Repair Society Score; MACl, matrix-induced ACI; VAS, visual analog scale for pain; IKDC, International Knee Documentation Committee Scale; MF, microfracture; HSS, hospital for special surgery knee score questionnaire; MRI, magnetic resonance imaging; CCI, characterized chondrocyte implantation; KOOS, Knee injury and Osteoarthritis Outcome Score.

to further treatment. Eventually, $52.3 \%$ of the originally included patients were evaluated. For $88 \%$ of the patients subjected to mosaicplasty and $68 \%$ of the ACI-P-treated patients complete clinical recovery was reported. The 2 methods were found to be clinically equivalent.

OAT and microfracture were compared in a prospective RCT in competitive or well-trained athletes by Gudas et al in $2006 .{ }^{86}$ Fifty-seven patients with full-thickness cartilage lesions or single OCD were randomized to either OAT or microfracture. The recommended continuous passive motion rehabilitation program was not applied. At 6, 12, 24, and 36 months after treatment, patients were evaluated. $93 \%$ of the OAT and $52 \%$ of the microfracture-treated group returned to presymptomatic sports level at 4-8 months after treatment. In terms of hospital for special surgery (HSS) and ICRS scores, magnetic resonance imaging (MRI), and histology and clinical assessments, significantly better results were reported for OAT compared with microfracture-treated athletes. ${ }^{86}$

In 2006, Gooding et al compared ACI-P with ACI-C in a prospective RCT including 68 patients. ${ }^{87}$ In $36.4 \%$ of the ACI-P vs none in the ACI-C-treated patients graft hypertrophy occurred, and shaving was required at 1 year after treatment. No significant differences between the 2 treatments were found in terms of Cincinnati, ICRS, and histology at 2 years after treatment. ${ }^{87}$

Knutsen et $\mathrm{al}^{47,88}$ reported their findings at 5 years in 2007 of a multicenter RCT comparing ACI-P with microfracture in 80 patients with single-cartilage defects of the femoral 
Table 2 Quality assessment and summary of the main conclusion of the RCTs

\begin{tabular}{|c|c|c|c|}
\hline Author & Treatments (n) & $\begin{array}{l}\text { RCT quality } \\
\text { score }\end{array}$ & Results \\
\hline \multirow[t]{2}{*}{ Horas et $\mathrm{al}^{83}$} & $\mathrm{ACl}-\mathrm{P}(20)$ & 3 & Meyer and Tegner: equal results \\
\hline & OAT (20) & & LKSS improvement both treatments, slower for ACl-P \\
\hline \multirow[t]{3}{*}{ Bentley et $\mathrm{al}^{84}$} & ACl-P and & 2 & ICRS score good/excellent: ACI-P 82\%, MP 34\% \\
\hline & $\mathrm{ACl}-\mathrm{C}(58)$ & & Cincinnatti/Stanmore good/excellent: ACI-P 88\%, MP 69\% \\
\hline & MP (42) & & Clinical outcome: $\mathrm{ACl}-\mathrm{P}>\mathrm{MP}$ \\
\hline \multirow[t]{2}{*}{ Bartlett et $\mathrm{al}^{70}$} & $\mathrm{ACl}-\mathrm{C}(44)$ & $\mathrm{I}$ & Cincinnati/Stanmore, VAS, histology: equal results \\
\hline & $\mathrm{MACl}(47)$ & & \\
\hline \multirow[t]{3}{*}{ Dozin et $a^{85}$} & $\mathrm{ACl}-\mathrm{P}(22)$ & 3 & $31.8 \%$ no further treatment needed following debridement \\
\hline & OAT (22) & & Complete clinical recovery: ACI-P 68\%, OAT 88\% \\
\hline & & & Clinical outcome: equal \\
\hline \multirow[t]{2}{*}{ Gudas et $\mathrm{al}^{86}$} & OAT (28) & 2 & ICRS and HSS good/excellent: OAT 96\%, MF 52\% \\
\hline & MF (29) & & Clinical outcome: OAT > MF \\
\hline \multirow[t]{2}{*}{ Gooding et $\mathrm{al}^{87}$} & $\mathrm{ACl}-\mathrm{P}(33)$ & 2 & Cincinnati, ICRS, histology: equal results \\
\hline & $\mathrm{ACl}-\mathrm{C}(35)$ & & Graft hypertrophy: ACI-P 36.4\%, ACl-C 0\% \\
\hline \multirow[t]{4}{*}{ Knutsen et $\mathrm{al}^{47,88}$} & $\mathrm{ACl}-\mathrm{P}(40)$ & 3 & LKSS, Kellgren and Lawrence, ICRS, Tegner, SF-36, histology: \\
\hline & MF (40) & & equal results \\
\hline & & & $77 \%$ satisfactory results and $23 \%$ failures in both groups \\
\hline & & & No relation between histology and clinical outcome \\
\hline \multirow[t]{2}{*}{ Saris et $\mathrm{al}^{61,89}$} & $\mathrm{CCl}(57)$ & 3 & KOOS: both significant improvement, $\mathrm{CCl}>\mathrm{MF}$ \\
\hline & MF (6I) & & \\
\hline
\end{tabular}

Notes: A summary of the results and conclusions are displayed per RCT. The quality of presented RCTs was assessed using the Jadad score ${ }^{82}$ ( $0-5$, a high score is an indication of high quality of the study). The comparison of single surgery approaches (MF, OAT) with double surgery approaches (all ACl) makes double blinding the procedure difficult for these surgical interventions; without double blinding the maximum Jadad score for RCTs is 3 .

Abbreviations: RCTs, randomized clinical trials; ACI-P, first generation autologous chondrocyte implantation (with periosteal coverage); OAT, osteochondral autograft transplantation; LKSS, Lysholm Knee Scoring Scale; ACI-C, second generation autologous chondrocyte implantation (with collagen coverage); MP, mosaicplasty; ICRS, International Cartilage Repair Society Score; MACI, matrix-induced ACl; VAS, visual analog scale for pain; MF, microfracture; HSS, hospital for special surgery knee score questionnaire; $\mathrm{CCl}$, characterized chondrocyte implantation; KOOS, Knee injury and Osteoarthritis Outcome Score.

condyle of the knee. After 5 years, 23\% failures were reported in both groups, defined as reoperation required due to symptoms as a result of lack of healing after the initial treatment. Shaving or trimming was necessary in $25 \%$ of the ACI-P and $10 \%$ of the microfracture-treated patients. ${ }^{47}$ This was not considered failure. No significant differences were found between both treatments in terms of clinical and radiographical outcome. Interestingly, no relation between histological findings and clinical outcome was observed. ${ }^{88}$

The results of a multicenter RCT comparing CCI (ChondroCelect) with microfracture at 36 months after treatment were reported by Saris et al ${ }^{61,89}$ in 2008 and 2009 . One hundred and eighteen patients with symptomatic lesions of the femoral condyle of the knee were randomized to one of the treatments. Based on findings in characterization of the autologous chondrocytes, 6 patients were not subjected to CCI treatment. It is not known whether these chondrocytes classified as not usable actually can result in compromised repair tissue. It was found that the longer the duration of the symptoms, the higher the improvement was of the Knee injury and Osteoarthritis Outcome Score (KOOS) of CCI-treated patients compared with microfracture-treated patients. The clinical outcome in terms of KOOS at 36 months after treatment showed signifi- cantly better results for CCI compared with microfracturetreated patients. ${ }^{89}$

Evaluating the currently available RCTs, within the two main objectives of articular cartilage repair, symptom relief and prevention of joint degeneration, we can conclude that all therapies show initial improvement measured with functional outcome scores. The comparison of single surgery approaches (microfracture, OAT) with double surgery approaches (all ACI) makes double blinding the procedure difficult for these RCTs. Therefore, none of the RCTs reached the maximum Jadad RCT quality score of 5 points; 4 of 8 RCTs scored the maximum of 3 points for unblinded RCTs and could be regarded as good quality RCTs. Considering prevention of early OA development, histological examinations have shown variable results, with a general suggestion of better tissue quality following ACI compared with microfracture and OAT. Arguments to assume that microfracture and OAT may result in worse longterm outcome and earlier OA development are fibrocartilage formation, donor-site morbidity, and the persistence of gaps between osteochondral plugs and surrounding cartilage. However, in general ACI is a two-stage procedure (harvesting of cartilage and a second open/arthroscopic implantation procedure) that may also lead to complications. For example, 
an increased inflammatory response and negative influences on joint propriocepsis following two procedures performed shortly after each other may also increase the risk for early OA development. The above-mentioned natural outcome studies have shown that it takes a long time for untreated cartilage defects to lead to detectable OA. Therefore, it may even take longer to judge whether extensive cell-based interventions protect joints from degenerating. Moreover, marrow stimulation shows good improvement in short- to mid-term follow-up. This may already be sufficient to protect joints from degeneration. Use of MRI techniques, such as delayed gadolinium-enhanced MRI of cartilage (dGEMRIC), or sensitive biomarkers for OA development are examples by which we can improve early judgment of cartilage repair tissue.

\section{MSCs for cartilage repair}

All the above-mentioned techniques make use of chondrocytes for articular cartilage repair with the exception of microfracture, whereas MSCs are accredited for the formation of repair tissue. For the treatment of cartilage defects, cells are needed in substantial amounts to fill the gap and to produce extracellular matrix of sufficient strength in a relatively short time compared with cartilage development in a growing joint. This requires in vitro cell expansion of harvested and enzymatically liberated chondrocytes with the risk of dedifferentiation and loss of redifferentiation capacity after expansion.

MSCs can be an attractive alternative cell source. MSCs have a good proliferative capacity in culture and have the potential to differentiate into different mesenchymal lineages, such as bone, cartilage, tendon, muscle, and fat. ${ }^{90}$ Chondrogenic differentiation is achieved when the cells, after expansion, are allowed to form three-dimensional aggregates in a chemically defined medium-containing transforming growth factor- $\beta$ (TGF- $\beta$ ) and dexamethasone. ${ }^{91}$

These multipotent progenitor cells can be derived from several tissues, including bone marrow, ${ }^{92}$ adipose tissue, ${ }^{93}$ joint-related tissues like synovial membrane, ${ }^{94}$ and infrapatellar fat. ${ }^{95}$ Furthermore, it has been shown that articular cartilage contains progenitor cells with the capacity to regenerate cartilage in vitro. ${ }^{96}$ In another study, undifferentiated progenitor cells were isolated from 7-dayold calf articular cartilage. ${ }^{97}$

Subsequent to their capacity to form repair tissue, MSCs have been shown to secrete a large spectrum of bioactive molecules in culture, including TGF- $\beta$, interleukin (IL)-10, IL-6, lymphocyte inhibitor factor, cyclooxygenase (COX)-1, and COX-2. ${ }^{98}$ These molecules are immunosuppressive; therefore, the secreted bioactive molecules are believed to provide a regenerative microenvironment for injured or ischemic adult tissues. This regenerative microenvironment referred to as trophic activity, provided by the presence of MSCs, limits the damage sustained by injury or ischemia and stimulates intrinsic regenerative responses. ${ }^{99}$

For similar reasons, MSCs have been shown to be a promising cell population for immunomodulatory therapy as they can modulate T-lymphocyte reaction both in vitro and in vivo. ${ }^{100}$ Le Blanc et al ${ }^{101}$ showed that ex vivo-expanded allogeneic MSCs were immunosuppressive, reverse established graft vs host disease, and prolonged graft survival in patients after bone marrow transplantation. MSC infusions have also been tested as a possible method to induce immunologic tolerance or to reduce the need for pharmacologic immunosuppression for organ transplantation. ${ }^{100}$

Furthermore, from cardiovascular research, we have learned that the microenvironment provided by injected MSCs, and not the initially believed transdifferentiation of MSCs into contractile cardiomyocytes, reduces the development of heart failure following myocardial infarction. ${ }^{102}$ From this point of view, one can hypothesize that a part of the observed effects of current cartilage repair techniques depend on this trophic activity. Undifferentiated or dedifferentiated cells, actors in the observed repair with microfracture and ACI techniques, may not only inhabit the cartilage defects and produce the necessary extracellular matrix but also provide a regenerative microenvironment. This may partly explain why investigators have found no distinct relation between repair cartilage histology and functional outcome. ${ }^{88}$ Future studies have to reveal whether we can further improve these techniques by optimizing trophic activity. Catabolic conditions in joints with cartilage defects and/or OA may be stopped or reversed by the continuous presence of MSC trophic activity.

Animal studies, using a combination of MSCs combined with different biomaterials and growth factors, have shown promising results. ${ }^{103}$ There are few clinical case-studies reporting the results of bone marrow-derived MSCs for cartilage defect repair. The MSCs are implanted in cartilage defects, seeded in collagen, and covered with periosteum. ${ }^{104}$ Others have injected culture-expanded MSCs percutaneously into the knee in an attempt to regenerate cartilage in OA patients. ${ }^{105}$ Currently, it is not known whether MSC treatments can give results similar to ACI or microfracture treatment. ${ }^{77} \mathrm{~A}$ recent observational cohort study compared bone marrow-derived MSCs with chondrocytes and found no differences in clinical outcome scores. ${ }^{106}$ The authors 
concluded that bone marrow-derived MSCs were as effective as chondrocytes for articular cartilage repair, with the advantage of one fewer knee intervention and minimized donor-site morbidity.

\section{Clinical issues and future perspectives \\ Which cells are responsible for repair?}

The presented cartilage repair techniques are designed to replace damaged articular cartilage, by supplying or attracting cells in sufficient amounts that produce extracellular matrix and thereby fill the gap. There is evidence to support the idea that the implanted culture-expanded chondrocytes or MSCs are relevant for cell-based therapies. ${ }^{107,108}$ In order to further optimize cell-based therapies, we need to know whether the implanted cells can be accredited for repair tissue formation by cell tracing in the joint. The fate of cells following in vivo implantation in humans and their exact role in regeneration remain unclear. It may appear that other cells are relevant for repair tissue formation, cells such as periosteal progenitor cells in ACI-P, ingrowth of subchondral marrow-cells, or synovial progenitor cells. Studies undertaken to determine the fate of implanted chondrocytes for in vivo follow-up include retroviral green fluorescence protein marking of cells, ${ }^{109}$ PKH26 fluorescent labeling of chondrocytes, ${ }^{107}$ and the use of "physicochemical labels" such as magnetic nanoparticles. ${ }^{110,111}$ An important advantage of magnetic nanoparticles like "superparamagnetic iron oxide"-labeling over other labeling techniques is that it enables clinical noninvasive in vivo cell tracking using MRI, without the need for harvesting biopsies. This allows for continuous follow-up of biological repair of articular cartilage without influencing the repair tissue or jeopardizing the patient with repeated interventions.

\section{Integrative cartilage repair}

An important prerequisite for durable repair of cartilage lesions is the integration of regenerated or transplanted cartilage with the surrounding native cartilage at the recipient site. Integrative cartilage repair is probably hindered by the lack of matrix-producing cells in wound edges caused by chondrocyte death induced by wounding of cartilage. In vitro experiments have shown a rapid onset of cell death in experimentally wounded hyaline cartilage. ${ }^{12,113}$ The acellularity is probably caused by a combination of chondrocyte loss from lesion edges, cartilage avascularity, absence of necrotic tissue removal, and the inability of chondrocytes to migrate through the tight extracellular matrix. Approaches to improve cell density at wound edges include use of cells in the interface region, enzymatic treatment, and use of immature constructs. Silverman et $\mathrm{al}^{114}$ studied the adhesion between native cartilage discs, using fibrin glue polymer alone or mixed with fresh articular chondrocytes. Their results demonstrated that adhesion of cartilage-to-cartilage can be improved by an increased amount of chondrocytes in the interface region.

The age and cell density of regenerated tissue influence the histological integration and its biomechanical strength. An increased cell density in the interface region by using immature constructs compared with mature constructs in an integration study was shown to improve biomechanical bonding strength and histological integration. ${ }^{115}$ In other studies highly purified collagenase treatment was used, which resulted in an increased wound edge cell density. This "vitalization" of wound edges with vital, matrix-producing cells at the cartilage-to-cartilage interface was shown to improve histological and biomechanical integrative cartilage repair. ${ }^{112,116,117}$ Enzymatic removal of proteoglycans or glycosaminoglycan (GAG) chains from the cartilage lesion edges by using chondroitinase $\mathrm{ABC}$, trypsin, or hyaluronidase has been shown to improve the initial adhesion of transplanted cells ${ }^{118}$ or cartilage-to-cartilage wound edges. ${ }^{119,120}$

Components of the synovial fluid may have an inhibitory effect on integrative cartilage repair. Proteoglycan 4 (PRG4 or lubricin), present in the synovial fluid, normally acting as a lubricant of articular surfaces was shown to strongly reduce cartilage integration. ${ }^{121}$

Integrative cartilage repair appears to be less of a problem for in situ cartilage regeneration (ACI and marrow stimulation) as compared with mature tissue transplantation (OAT or mature tissue-engineered constructs). However, cell-based cartilage repair does need improvement of integrative repair if we plan to extend the indications for cartilage repair, eg, with defect treatment in older patients or in more degenerative joints. Integration of in situ induced neocartilage with older and thus lower cell density cartilage or degenerated cartilage wound edges probably benefits from the above-mentioned interventions.

\section{Outcome parameters}

Long-term follow-up of patients is required in order to determine whether cartilage defect repair prevents patients from OA development, as this can take many years. Clinical outcome scores and histological grading of biopsies (in the currently available RCTs often from a small part of the study subjects) are now used to follow the repair process. Methods 
that are both objective and noninvasive with the ability to follow the repair process and/or the development and progression of OA in time would be of large clinical value. Currently, dGEMRIC, in which a gadolinium-containing contrast agent $\left(\mathrm{Gd}^{\left.-\mathrm{DPTA}^{2}\right)}\right.$ is injected intravenously followed by MRI, is evolving as a noninvasive method to provide information about the quality of cartilage and repair tissue. ${ }^{122,123}$ In damaged cartilage, the GAG content and thereby charge is different compared with healthy cartilage, which also affects mechanical properties. ${ }^{124}$ These charge changes are detectable using dGEMRIC as a consequence of differences in GdDPTA $^{2}$ uptake in the cartilage. ${ }^{122,125}$ Recently, dGEMRIC has been studied for follow-up of patients treated with ACI or ACI-derived treatments. ${ }^{126-128}$ For ACI-P-treated patients at 9-18 years after treatment, the quality of repair tissue was found to be comparable with surrounding native cartilage; however, no correlation between dGEMRIC results and KOOS was found. ${ }^{128}$ Studies using dGEMRIC for evaluation of ACI or ACI-derived treatments are so far conducted in small study populations (5-36 patients). ${ }^{126-128}$ To our knowledge, there is only one animal study from which it is concluded that dGEMRIC might be useful for microfracture follow-up. ${ }^{129}$ It is evident that larger studies and RCTs are required in order to truly assess the potential of dGEMRIC in follow-up of treated cartilage defects and the early detection of development and progression of OA.

\section{Bioactive materials to improve intrinsic healing capacity}

Earlier in this review, we described the use of augmentation of the microfracture technique by using biomaterials. Stimulation of the body's intrinsic healing capacity by the use of bioactive biomaterials is attractive because it can yield an off-the-shelf product. Research focuses on the attraction of cells from the environment (bone marrow, synovium, or even the cartilage) into a scaffold material and to stimulate these cells to form cartilage matrix. Many different types of biomaterials, both synthetic and natural, are being developed, modified, and evaluated. These biomaterials can be made bioactive by incorporation of growth factors or gene vectors to improve cell ingrowth, cell proliferation, or matrix production. Even anti-inflammatory factors can be incorporated to inhibit inflammatory processes, which are known to have negative effects on cartilage repair. Controlled release of these factors in time and may be even sequential release of a number of factors will be necessary for optimal control of the tissue repair process. Research in this area can be expected to reveal new suitable products to improve cartilage repair in the future.

\section{Regulatory obstacles}

Stringent regulatory requirements by the US Food and Drug Administration and the European Advanced Therapy Medicinal Therapy regulations have made industrial development of cell therapeutic applications more difficult. Therefore, simpler, and cheaper, single-stage methods, where cell culture is avoided, are receiving more and more attention. Examples of these single-stage methods are the earlier mentioned bone marrow stimulation techniques augmented with biomaterials and the cartilage autograft implantation system (dePuy Mitek Inc., Raynham, MA) where cartilage is minced, added to a synthetic scaffold, and fixed cartilage defects with resorbable staples. More developments are to be expected such as INSTRUCT, a cartilage repair method that is currently undergoing a pilot study in patients where the construct is prepared in the operation theater by combining isolated primary chondrocytes with freshly isolated bone marrow cells seeded in a mechanically functional scaffold (CellCoTEc, Bilthoven, The Netherlands).

\section{Conclusion and future directions}

The intrinsic repair capacity of articular cartilage defects is limited, and we believe that these lesions contribute to the development of early OA. The goals of cartilage defect repair should always be a combination of symptom relief and prevention of early joint degeneration. From natural outcome studies, we have learned that it may take many years for isolated cartilage lesions to lead to degenerative changes. However, most cartilage lesions are associated with more extensive joint injuries, contributing to the risk for OA development. For this reason, results from RCTs, with selected patients, cannot fully elucidate the value of current cartilage repair techniques for often more extensive injuries. The above-presented RCTs show an improvement of symptoms following use of current repair techniques with an advantage for cell-based techniques, but they only suggest that the risk for joint degeneration can be reduced.

Successful repair techniques for isolated cartilage defects in otherwise healthy joints may, in the future, be translated to treatment of more extensively degenerated joint diseases such as OA. In degenerative joints, repair of cartilage lesions alone is probably not enough to restore joint function. Because of the progressive nature of OA and the involvement of many different tissues in the joint, this new repair tissue will probably be degraded by a combination of catabolic synovial 
factors and the altered subchondral bone lying underneath the repaired cartilage. It will, therefore, be necessary to develop a combination of therapies to modulate the degenerative processes, either surgically or pharmacologically, before or at the time of application of a cartilage repair technique.

MSCs can be an attractive cell source for cartilage repair, not only because they are easily harvested, have a good proliferative capacity, and can differentiate into chondrocytes but also because of their trophic activity. MSCs have been shown to secrete a large spectrum of bioactive molecules resulting in a regenerative microenvironment potentially limiting damage and stimulating intrinsic regenerative responses.

\section{Acknowledgments}

ML van Melle is supported by a research grant of the Dutch Arthritis Association. The authors declare the absence of competing interests and confirm their independence regarding the content of this manuscript.

\section{Disclosure}

The authors report no conflicts of interest in this work.

\section{References}

1. Buckwalter JA, Mankin HJ. Articular cartilage: degeneration and osteoarthritis, repair, regeneration, and transplantation. Instr Course Lect. 1998;47:487-504.

2. Hunziker EB. Articular cartilage repair: basic science and clinical progress. A review of the current status and prospects. Osteoarthritis Cartilage. 2002;10(6):432-463.

3. Messner K, Gillquist J. Cartilage repair: a critical review. Acta Orthop Scand. 1996;67(5):523-529.

4. Brittberg M, Lindahl A, Nilsson A, Ohlsson C, Isaksson O, Peterson L. Treatment of deep cartilage defects in the knee with autologous chondrocyte transplantation. $N$ Engl J Med. 1994;331(14):889-895.

5. Mankin HJ. Chondrocyte transplantation - one answer to an old question. $N$ Engl J Med. 1994;331(14):940-941.

6. Shapiro F, Koide S, Glimcher MJ. Cell origin and differentiation in the repair of full-thickness defects of articular cartilage. J Bone Joint Surg Am. 1993;75(4):532-553.

7. Mankin HJ. The response of articular cartilage to mechanical injury. $J$ Bone Joint Surg Am. 1982;64(3):460-466.

8. Brittberg M, Peterson L. Introduction to an articular cartilage classification. ICRS Newslett. 1998;1:8.

9. Hjelle K, Solheim E, Strand T, Muri R, Brittberg M. Articular cartilage defects in 1,000 knee arthroscopies. Arthroscopy. 2002;18(7): 730-734.

10. Aroen A, Loken S, Heir S, et al. Articular cartilage lesions in 993 consecutive knee arthroscopies. Am J Sports Med. 2004;32(1): 211-215.

11. Noyes FR, Bassett RW, Grood ES, Butler DL. Arthroscopy in acute traumatic hemarthrosis of the knee. Incidence of anterior cruciate tears and other injuries. J Bone Joint Surg Am. 1980;62(5):687-95, 757.

12. Hardaker WT Jr, Garrett WE Jr, Bassett FH III. Evaluation of acute traumatic hemarthrosis of the knee joint. South Med J. 1990;83(6): 640-644

13. Maffulli N, Binfield PM, King JB, Good CJ. Acute haemarthrosis of the knee in athletes. A prospective study of 106 cases. J Bone Joint Surg Br. 1993;75(6):945-949.
14. Curl WW, Krome J, Gordon ES, Rushing J, Smith BP, Poehling GG. Cartilage injuries: a review of 31,516 knee arthroscopies. Arthroscopy. 1997;13(4):456-460.

15. Shelbourne KD, Jari S, Gray T. Outcome of untreated traumatic articular cartilage defects of the knee: a natural history study. J Bone Joint Surg Am. 2003;85-A Suppl 2:8-16.

16. Outerbridge RE. The etiology of chondromalacia patellae. J Bone Joint Surg Br. 1961;43-B:752-757.

17. Linden B. Osteochondritis dissecans of the femoral condyles: a longterm follow-up study. J Bone Joint Surg Am. 1977;59(6):769-776.

18. Widuchowski W, Widuchowski J, Faltus R, et al. Long-term clinical and radiological assessment of untreated severe cartilage damage in the knee: a natural history study. Scand J Med Sci Sports. Epub 2010 Jan 31.

19. Gelber AC, Hochberg MC, Mead LA, Wang NY, Wigley FM, Klag MJ Joint injury in young adults and risk for subsequent knee and hip osteoarthritis. Ann Intern Med. 2000;133(5):321-328.

20. Yen YM, Cascio B, O’Brien L, Stalzer S, Millett PJ, Steadman JR. Treatment of osteoarthritis of the knee with microfracture and rehabilitation. Med Sci Sports Exerc. 2008;40(2):200-205.

21. Gomoll AH, Kang RW, Chen AL, Cole BJ. Triad of cartilage restoration for unicompartmental arthritis treatment in young patients: meniscus allograft transplantation, cartilage repair and osteotomy. J Knee Surg. 2009;22(2):137-141.

22. Lawrence RC, Felson DT, Helmick CG, et al. Estimates of the prevalence of arthritis and other rheumatic conditions in the United States. Part II. Arthritis Rheum. 2008;58(1):26-35.

23. Michaud CM, McKenna MT, Begg S, et al. The burden of disease and injury in the United States 1996. Popul Health Metr. 2006;4:11.

24. Hootman JM, Helmick CG. Projections of US prevalence of arthritis and associated activity limitations. Arthritis Rheum. 2006;54(1): 226-229.

25. Hangody L, Feczko P, Bartha L, Bodo G, Kish G. Mosaicplasty for the treatment of articular defects of the knee and ankle. Clin Orthop Relat Res. 2001;(391 Suppl 1):S328-S336.

26. Bobic V. [Autologous osteo-chondral grafts in the management of articular cartilage lesions] Die Verwendung von autologen KnochenKnorpel-Transplantaten in der Behandlung von Gelenkknorpellasionen. Orthopade. 1999;28(1):19-25.

27. Hangody L, Vasarhelyi G, Hangody LR, et al. Autologous osteochondral grafting - technique and long-term results. Injury. 2008;39 Suppl 1:S32-S39.

28. Richter W. Mesenchymal stem cells and cartilage in situ regeneration. J Intern Med. 2009;266(4):390-405.

29. Buckwalter JA. Articular cartilage injuries. Clin Orthop Relat Res. 2002;(402):21-37.

30. Pridie KH. A method of resurfacing osteoarthritic knee joints. J Bone Joint Surg Br. 1959;41:618-619.

31. Steadman JR, Rodkey WG, Briggs KK, Rodrigo JJ. [The microfracture technic in the management of complete cartilage defects in the knee joint] Die Technik der Mikrofrakturierung zur Behandlung von kompletten Knorpeldefekten im Kniegelenk. Orthopade. 1999;28(1):26-32.

32. Steinwachs MR, Guggi T, Kreuz PC. Marrow stimulation techniques. Injury. 2008;39 Suppl 1:S26-S31.

33. Mithoefer K, Williams RJ III, Warren RF, et al. Chondral resurfacing of articular cartilage defects in the knee with the microfracture technique. Surgical technique. J Bone Joint Surg Am. 2006;88 Suppl 1(Pt 2):294-304.

34. Steadman JR, Rodkey WG, Rodrigo JJ. Microfracture: surgical technique and rehabilitation to treat chondral defects. Clin Orthop Relat Res. 2001;(391 Suppl 1):S362-S369.

35. Frisbie DD, Cross MW, McIlwraith CW. A comparative study of articular cartilage thickness in the stifle of animal species used in human preclinical studies compared to articular cartilage thickness in the human knee. Vet Comp Orthop Traumatol. 2006;19(3):142-146.

36. Steadman JR, Rodkey WG, Briggs KK. Microfracture: Its history and experience of the developing surgeon. Cartilage. 2010;1(2): $78-86$. 
37. Frisbie DD, Trotter GW, Powers BE, et al. Arthroscopic subchondral bone plate microfracture technique augments healing of large chondral defects in the radial carpal bone and medial femoral condyle of horses. Vet Surg. 1999;28(4):242-255.

38. Frisbie DD, Oxford JT, Southwood L, et al. Early events in cartilage repair after subchondral bone microfracture. Clin Orthop Relat Res. 2003;(407):215-227.

39. Frisbie DD, Morisset S, Ho CP, Rodkey WG, Steadman JR, McIlwraith CW. Effects of calcified cartilage on healing of chondral defects treated with microfracture in horses. Am J Sports Med. 2006; 34(11):1824-1831.

40. Morisset S, Frisbie DD, Robbins PD, Nixon AJ, McIlwraith CW. IL-1ra/IGF-1 gene therapy modulates repair of microfractured chondral defects. Clin Orthop Relat Res. 2007;462:221-228.

41. Mithoefer K, Williams RJ III, Warren RF, et al. The microfracture technique for the treatment of articular cartilage lesions in the knee. A prospective cohort study. J Bone Joint Surg Am. 2005;87(9): 1911-1920.

42. Brown WE, Potter HG, Marx RG, Wickiewicz TL, Warren RF. Magnetic resonance imaging appearance of cartilage repair in the knee. Clin Orthop Relat Res. 2004;(422):214-223.

43. Wilk KE, Macrina LC, Reinold MM. Rehabilitation following microfracture of the knee. Cartilage. 2010;1(2):96-107.

44. Steadman JR, Rodkey WG, Singleton SB, Briggs KK. Microfracture technique for full-thickness chondral defects: technique and clinical results. Op Tech Orthop. 1997;7:300-304

45. Hagerman GR, Atkins JA, Dillman C. Rehabilitation of chondral injuries and chronic degenerative arthritis of the knee in the athlete. Oper Tech Sports Med. 1995;3:127-135.

46. Gill TJ. The treatment of articular cartilage defects using microfracture and debridement. Am J Knee Surg. 2000;13(1):33-40.

47. Knutsen G, Engebretsen L, Ludvigsen TC, et al. Autologous chondrocyte implantation compared with microfracture in the knee. A randomized trial. J Bone Joint Surg Am. 2004;86-A(3): 455-464.

48. Mithoefer K, McAdams T, Williams RJ, Kreuz PC, Mandelbaum BR. Clinical efficacy of the microfracture technique for articular cartilage repair in the knee: an evidence-based systematic analysis. Am J Sports Med. 2009;37(10):2053-2063.

49. Gille J, Schuseil E, Wimmer J, Gellissen J, Schulz AP, Behrens P. Midterm results of autologous matrix-induced chondrogenesis for treatment of focal cartilage defects in the knee. Knee Surg Sports Traumatol Arthrosc. Epub 2010 Feb 2.

50. Hoemann CD, Hurtig M, Rossomacha E, et al. Chitosan-glycerol phosphate/blood implants improve hyaline cartilage repair in ovine microfracture defects. J Bone Joint Surg Am. 2005;87(12): 2671-2686.

51. Chevrier A, Hoemann CD, Sun J, Buschmann MD. Chitosan-glycerol phosphate/blood implants increase cell recruitment, transient vascularization and subchondral bone remodeling in drilled cartilage defects. Osteoarthritis Cartilage. 2007;15(3):316-327.

52. Buschmann MD, Hoemann CD, Hurtig MB, Shive MS. Cartilage repair using an injectable chitosan-based cell delivery method. In: Williams RJ, editor. Cartilage Repair Strategies. Totawa, NJ: Humana Press; 2007.

53. Shive MS, Hoemann C, Restrepo A, et al. BST-CarGel: in situ chondro induction for cartilage repair. Op Tech Orthop. 2006;16: 271-278.

54. Dorotka R, Windberger U, Macfelda K, Bindreiter U, Toma C, Nehrer S. Repair of articular cartilage defects treated by microfracture and a threedimensional collagen matrix. Biomaterials. 2005;26(17): 3617-3629.

55. Strauss E, Schachter A, Frenkel S, Rosen J. The efficacy of intra-articular hyaluronan injection after the microfracture technique for the treatment of articular cartilage lesions. Am J Sports Med. 2009; 37(4):720-726.

56. Strauss EJ, Barker JU, Kercher JS, Cole B, Mithoefer K. Augmentation strategies following the microfracture technique for repair of focal chondral defects. Cartilage. 2010;1(2):145-152.
57. Kramer J, Bohrnsen F, Lindner U, Behrens P, Schlenke P, Rohwedel J. In vivo matrix-guided human mesenchymal stem cells. Cell Mol Life Sci. 2006;63(5):616-626.

58. Shah MR, Kaplan KM, Meislin RJ, Bosco JA III. Articular cartilage restoration of the knee. Bull NYU Hosp Jt Dis. 2007;65(1): 51-60.

59. Sohn DH, Lottman LM, Lum LY, et al. Effect of gravity on localization of chondrocytes implanted in cartilage defects. Clin Orthop Relat Res. 2002;(394):254-262.

60. Marlovits S, Zeller P, Singer P, Resinger C, Vecsei V. Cartilage repair: generations of autologous chondrocyte transplantation. Eur J Radiol. 2006;57(1):24-31.

61. Saris DB, Vanlauwe J, Victor J, et al. Characterized chondrocyte implantation results in better structural repair when treating symptomatic cartilage defects of the knee in a randomized controlled trial vs microfracture. Am J Sports Med. 2008;36(2):235-246.

62. Brittberg M. Autologous chondrocyte implantation - technique and long-term follow-up. Injury. 2008;39 Suppl 1:S40-S49.

63. Drobnic M, Radosavljevic D, Cor A, Brittberg M, Strazar K. Debridement of cartilage lesions before autologous chondrocyte implantation by open or transarthroscopic techniques: a comparative study using post-mortem materials. J Bone Joint Surg Br. 2010;92(4): 602-608.

64. Simon TM, Jackson DW. Articular cartilage: injury pathways and treatment options. Sports Med Arthrosc. 2006;14(3):146-154.

65. Krishnan SP, Skinner JA, Bartlett W, et al. Who is the ideal candidate for autologous chondrocyte implantation? J Bone Joint Surg Br. 2006; 88(1):61-64.

66. Peterson L, Brittberg M, Kiviranta I, Akerlund EL, Lindahl A. Autologous chondrocyte transplantation. Biomechanics and long-term durability. Am J Sports Med. 2002;30(1):2-12.

67. Roberts S, McCall IW, Darby AJ, et al. Autologous chondrocyte implantation for cartilage repair: monitoring its success by magnetic resonance imaging and histology. Arthritis Res Ther. 2003;5(1): R60-R73.

68. Moseley JB Jr, Anderson AF, Browne JE, et al. Long-term durability of autologous chondrocyte implantation: a multicenter, observational study in US patients. Am J Sports Med. 2010;38(2):238-246.

69. Browne JE, Anderson AF, Arciero R, et al. Clinical outcome of autologous chondrocyte implantation at 5 years in US subjects. Clin Orthop Relat Res. 2005;(436):237-245.

70. Bartlett W, Skinner JA, Gooding CR, et al. Autologous chondrocyte implantation vs matrix-induced autologous chondrocyte implantation for osteochondral defects of the knee: a prospective, randomised study. J Bone Joint Surg Br. 2005;87(5):640-645.

71. Pelttari K, Lorenz H, Boeuf S, et al. Secretion of matrix metalloproteinase 3 by expanded articular chondrocytes as a predictor of ectopic cartilage formation capacity in vivo. Arthritis Rheum. 2008;58(2): 467-474.

72. Giannoni P, Crovace A, Malpeli M, et al. Species variability in the differentiation potential of in vitro-expanded articular chondrocytes restricts predictive studies on cartilage repair using animal models. Tissue Eng. 2005;11(1-2):237-248.

73. Tuan RS. Stemming cartilage degeneration: adult mesenchymal stem cells as a cell source for articular cartilage tissue engineering. Arthritis Rheum. 2006;54(10):3075-3078.

74. Safran MR, Seiber K. The evidence for surgical repair of articular cartilage in the knee. J Am Acad Orthop Surg. 2010;18(5):259-266.

75. Bekkers JE, Inklaar M, Saris DB. Treatment selection in articular cartilage lesions of the knee: a systematic review. Am J Sports Med. 2009;37 Suppl 1:S148-S155.

76. Vasiliadis HS, Wasiak J, Salanti G. Autologous chondrocyte implantation for the treatment of cartilage lesions of the knee: a systematic review of randomized studies. Knee Surg Sports Traumatol Arthrosc. Epub 2010 Feb 2.

77. van Osch GJ, Brittberg M, Dennis JE, et al. Cartilage repair: past and future - lessons for regenerative medicine. J Cell Mol Med. 2009; 13(5):792-810. 
78. Vavken P, Samartzis D. Effectiveness of autologous chondrocyte implantation in cartilage repair of the knee: a systematic review of controlled trials. Osteoarthritis Cartilage. 2010;18(6):857-863.

79. Ruano-Ravina A, Jato Diaz M. Autologous chondrocyte implantation: a systematic review. Osteoarthritis Cartilage. 2006;14(1):47-51.

80. Smith GD, Knutsen G, Richardson JB. A clinical review of cartilage repair techniques. J Bone Joint Surg Br. 2005;87(4):445-449.

81. Wasiak J, Clar C, Villanueva E. Autologous cartilage implantation for full thickness articular cartilage defects of the knee. Cochrane Database Syst Rev. 2006;3:CD003323.

82. Jadad AR, Moore RA, Carroll D, et al. Assessing the quality of reports of randomized clinical trials: is blinding necessary? Control Clin Trials. 1996;17(1):1-12.

83. Horas U, Pelinkovic D, Herr G, Aigner T, Schnettler R. Autologous chondrocyte implantation and osteochondral cylinder transplantation in cartilage repair of the knee joint. A prospective, comparative trial. $J$ Bone Joint Surg Am. 2003;85-A(2):185-192.

84. Bentley G, Biant LC, Carrington RW, et al. A prospective, randomised comparison of autologous chondrocyte implantation vs mosaicplasty for osteochondral defects in the knee. J Bone Joint Surg Br. 2003; 85(2):223-230.

85. Dozin B, Malpeli M, Cancedda R, et al. Comparative evaluation of autologous chondrocyte implantation and mosaicplasty: a multicentered randomized clinical trial. Clin J Sport Med. 2005;15(4): 220-226.

86. Gudas R, Stankevicius E, Monastyreckiene E, Pranys D, Kalesinskas RJ. Osteochondral autologous transplantation vs microfracture for the treatment of articular cartilage defects in the knee joint in athletes. Knee Surg Sports Traumatol Arthrosc. 2006;14(9):834-842.

87. Gooding CR, Bartlett W, Bentley G, Skinner JA, Carrington R, Flanagan A. A prospective, randomized study comparing two techniques of autologous chondrocyte implantation for osteochondral defects in the knee: Periosteum covered vs type I/III collagen covered. Knee. 2006;13(3):203-210.

88. Knutsen G, Drogset JO, Engebretsen L, et al. A randomized trial comparing autologous chondrocyte implantation with microfracture. Findings at five years. J Bone Joint Surg Am. 2007;89(10): 2105-2112.

89. Saris DB, Vanlauwe J, Victor J, et al. Treatment of symptomatic cartilage defects of the knee: characterized chondrocyte implantation results in better clinical outcome at 36 months in a randomized trial compared to microfracture. Am J Sports Med. 2009;37 Suppl 1: 10S-19S.

90. Pittenger MF, Mackay AM, Beck SC, et al. Multilineage potential of adult human mesenchymal stem cells. Science. 1999;284(5411): 143-147.

91. Johnstone B, Hering TM, Caplan AI, Goldberg VM, Yoo JU. In vitro chondrogenesis of bone marrow-derived mesenchymal progenitor cells. Exp Cell Res. 1998;238(1):265-272.

92. Noth U, Osyczka AM, Tuli R, Hickok NJ, Danielson KG, Tuan RS. Multilineage mesenchymal differentiation potential of human trabecular bone-derived cells. J Orthop Res. 2002;20(5):1060-1069.

93. Zuk PA. The Adipose-derived stem cell: looking back and looking ahead. Mol Biol Cell. 2010;21(11):1783-1787.

94. De Bari C, Dell'Accio F, Luyten FP. Human periosteum-derived cells maintain phenotypic stability and chondrogenic potential throughout expansion regardless of donor age. Arthritis Rheum. 2001; 44(1):85-95.

95. Wickham MQ, Erickson GR, Gimble JM, Vail TP, Guilak F. Multipotent stromal cells derived from the infrapatellar fat pad of the knee. Clin Orthop Relat Res. 2003;(412):196-212.

96. Bos PK, Kops N, Verhaar JA, van Osch GJ. Cellular origin of neocartilage formed at wound edges of articular cartilage in a tissue culture experiment. Osteoarthritis Cartilage. 2008;16(2):204-211.

97. Dowthwaite GP, Bishop JC, Redman SN, et al. The surface of articular cartilage contains a progenitor cell population. J Cell Sci. 2004; 117(Pt 6):889-897.
98. Bouffi C, Djouad F, Mathieu M, Noel D, Jorgensen C. Multipotent mesenchymal stromal cells and rheumatoid arthritis: risk or benefit? Rheumatology (Oxford). 2009;48(10):1185-1189.

99. Caplan AI. Why are MSCs therapeutic? New data: new insight. J Pathol. 2009;217(2):318-324.

100. Dahlke MH, Hoogduijn M, Eggenhofer E, et al. Toward MSC in solid organ transplantation: 2008 position paper of the MISOT study group. Transplantation. 2009;88(5):614-619.

101. Le Blanc K, Frassoni F, Ball L, et al. Mesenchymal stem cells for treatment of steroid-resistant, severe, acute graft-vs-host disease: a phase II study. Lancet. 2008;371(9624):1579-1586.

102. Passier R, van Laake LW, Mummery CL. Stem-cell-based therapy and lessons from the heart. Nature. 2008;453(7193):322-329.

103. Pelttari K, Steck E, Richter W. The use of mesenchymal stem cells for chondrogenesis. Injury. 2008;39 Suppl 1:S58-S65.

104. Wakitani S, Imoto K, Yamamoto T, Saito M, Murata N, Yoneda M. Human autologous culture expanded bone marrow mesenchymal cell transplantation for repair of cartilage defects in osteoarthritic knees. Osteoarthritis Cartilage. 2002;10(3):199-206.

105. Centeno CJ, Schultz JR, Cheever M, Robinson B, Freeman M, Marasco W. Safety and complications reporting on the re-implantation of culture-expanded mesenchymal stem cells using autologous platelet lysate technique. Curr Stem Cell Res Ther. 2010;5(1):81-93.

106. Nejadnik H, Hui JH, Feng Choong EP, Tai BC, Lee EH. Autologous bone marrow-derived mesenchymal stem cells vs autologous chondrocyte implantation: an observational cohort study. Am J Sports Med. 2010;38(6):1110-1116

107. Dell'Accio F, Vanlauwe J, Bellemans J, Neys J, De Bari C, Luyten FP. Expanded phenotypically stable chondrocytes persist in the repair tissue and contribute to cartilage matrix formation and structural integration in a goat model of autologous chondrocyte implantation. J Orthop Res. 2003;21(1):123-131.

108. Min BH, Woo JI, Kim WH, et al. The fate of implanted autologous chondrocytes in regenerated articular cartilage. Proc Inst Mech Eng $H$. 2007;221(5):461-465.

109. Hirschmann F, Verhoeyen E, Wirth D, Bauwens S, Hauser H, Rudert M. Vital marking of articular chondrocytes by retroviral infection using green fluorescence protein. Osteoarthritis Cartilage. 2002;10(2):109-118

110. van Buul GM, Farrell E, Kops N, et al. Ferumoxides-protamine sulfate is more effective than ferucarbotran for cell labeling: implications for clinically applicable cell tracking using MRI. Contrast Media Mol Imaging. 2009;4(5):230-236.

111. Farrell E, Wielopolski P, Pavljasevic P, et al. Effects of iron oxide incorporation for long term cell tracking on MSC differentiation in vitro and in vivo. Biochem Biophys Res Commun. 2008;369(4): 1076-1081.

112. Bos PK, DeGroot J, Budde M, Verhaar JA, van Osch GJ. Specific enzymatic treatment of bovine and human articular cartilage: implications for integrative cartilage repair. Arthritis Rheum. 2002; 46(4):976-985.

113. Tew SR, Kwan AP, Hann A, Thomson BM, Archer CW. The reactions of articular cartilage to experimental wounding: role of apoptosis. Arthritis Rheum. 2000;43(1):215-225.

114. Silverman RP, Bonasser L, Passaretti D, Randolph MA, Yaremchuk MJ. Adhesion of tissue-engineered cartilate to native cartilage. Plast Reconstr Surg. 2000;105(4):1393-1398.

115. Obradovic B, Martin I, Padera RF, Treppo S, Freed LE, VunjakNovakovic G. Integration of engineered cartilage. J Orthop Res. 2001 19(6):1089-1097.

116. van de Breevaart Bravenboer J, In der Maur CD, Bos PK, et al Improved cartilage integration and interfacial strength after enzymatic treatment in a cartilage transplantation model. Arthritis Res Ther. 2004; 6(5):R469-R476.

117. Janssen LM, In der Maur CD, Bos PK, Hardillo JA, van Osch GJ. Short-duration enzymatic treatment promotes integration of a cartilage graft in a defect. Ann Otol Rhinol Laryngol. 2006;115(6):461-468. 
118. Mochizuki Y, Goldberg V, Caplan A. Enzymatical digestion for the repair of superficial articular cartilage lesions. Trans Orthop Res Soc. 1993;39:728.

119. Hunziker EB, Kapfinger E. Removal of proteoglycans from the surface of defects in articular cartilage transiently enhances coverage by repair cells. J Bone Joint Surg Br. 1998;80(1):144-150.

120. Lee MC, Sung KL, Kurtis MS, Akeson WH, Sah RL. Adhesive force of chondrocytes to cartilage. Effects of chondroitinase ABC. Clin Orthop. 2000(370):286-294.

121. Schaefer DB, Wendt D, Moretti M, et al. Lubricin reduces cartilage cartilage integration. Biorheology. 2004;41(3-4):503-508.

122. Tiderius CJ, Svensson J, Leander P, Ola T, Dahlberg L. dGEMRIC (delayed gadolinium-enhanced MRI of cartilage) indicates adaptive capacity of human knee cartilage. Magn Reson Med. 2004;51(2): 286-290.

123. Bashir A, Gray ML, Burstein D. Gd-DTPA2-as a measure of cartilage degradation. Magn Reson Med. 1996;36(5):665-673.

124. Maroudas A, ed. Physicochemical properties of articular cartilage. London: Pitman Medical; 1979.
125. Gray ML, Burstein D, Kim YJ, Maroudas A. 2007 Elizabeth Winston Lanier Award Winner. Magnetic resonance imaging of cartilage glycosaminoglycan: basic principles, imaging technique, and clinical applications. J Orthop Res. 2008;26(3):281-291.

126. Trattnig S, Marlovits S, Gebetsroither S, et al. Three-dimensional delayed gadolinium-enhanced MRI of cartilage (dGEMRIC) for in vivo evaluation of reparative cartilage after matrix-associated autologous chondrocyte transplantation at 3.0T: Preliminary results. JMagn Reson Imaging. 2007;26(4):974-982.

127. Domayer SE, Welsch GH, Nehrer S, et al. T2 mapping and dGEMRIC after autologous chondrocyte implantation with a fibrin-based scaffold in the knee: preliminary results. Eur J Radiol. 2010;73(3): 636-642.

128. Vasiliadis HS, Danielson B, Ljungberg M, McKeon B, Lindahl A, Peterson L. Autologous chondrocyte implantation in cartilage lesions of the knee: long-term evaluation with magnetic resonance imaging and delayed gadolinium-enhanced magnetic resonance imaging technique. Am J Sports Med. 2010;38(5):943-949.

129. Watanabe A, Boesch C, Anderson SE, Brehm W, Mainil Varlet P. Ability of dGEMRIC and T2 mapping to evaluate cartilage repair after microfracture: a goat study. Osteoarthritis Cartilage. 2009;17(10): 1341-1349.
Open Access Surgery

\section{Publish your work in this journal}

Open Access Surgery is an international, peer-reviewed, open access journal that focuses on all aspects of surgical procedures and interventions. Patient care around the peri-operative period and patient outcomes post surgery are key topics. All grades of surgery from minor cosmetic interventions to major surgical procedures are covered. Novel techniques

Submit your manuscript here: http://www.dovepress.com/open-access-surgery-journal

\section{Dovepress}

and the utilization of new instruments and materials, including implants and prostheses that optimize outcomes constitute major areas of interest. The manuscript management system is completely online and includes a very quick and fair peer-review system. Visit http://www.dovepress.com/ testimonials.php to read real quotes from published authors. 